\title{
ATYPICAL PNEUMONIA AND PSITTACOSIS
}

\author{
BY JOSEPH E. SMADEL \\ (From the Hospital of The Rockefeller Institute for Medical Research, New York City)
}

(Received for publication July 24, 1942)

Attention has been focused in recent years on the acute infectious pulmonary disease which, for want of a better name, has been called "atypical pneumonia." Many descriptions of this type of malady have appeared ( 1 to 10 ), and several different non-bacterial infectious agents have been incriminated or identified as the cause of certain of the outbreaks $(3,10$ to 14$)$. These findings indicate that atypical pneumonia is a clinicalpathological entity which has a diverse etiology. One of the first approaches to the problem of atypical pneumonia should be the establishment of an etiological diagnosis whenever possible. In this way, certain types of cases can be removed from the general group and studied in a more intelligent manner.

The fact that infection with psittacosis virus is responsible for certain cases of non-bacterial pneumonia is well recognized. For example, pulmonary consolidation is a characteristic feature of classical psittacosis in man, caused by psittacine strains of the virus (15). Furthermore, Eaton and his co-workers (13) have demonstrated that a strain of psittacosis virus, which is practically indistinguishable $(13,16$ to 18$)$ from the agent designated meningopneumonitis by Francis and Magill (19), can cause pneumonia and death in human beings. Finally, Meyer and his associates (20 to 22) have emphasized the role of other members of the psittacosis group in producing bronchopneumonia; recently, they have laid stress on the transmission of certain strains of the virus to man from infected pigeons and chickens.

It is appropriate to discuss at once the confusion that exists regarding the exact relationship of a number of viruses, which have been isolated by several groups of workers from different sources, and which have many characteristics in common with one another and with classical psittacine strains of the virus of psittacosis. Thus, Rake, Eaton and Shaffer (16) have demonstrated that sera of patients convalescent from lymphogranuloma venereum, from psittacosis of parrot or pigeon origin, and from the pneumonitis studied by Eaton, all possess an antibody which fixes complement in the presence of antigen prepared from the virus of lymphogranuloma venereum, of psittacosis, or of meningopneumonitis. Furthermore, these workers, as well as Pinkerton and Moragues (17), have noted similarities in the morphological and tinctorial qualities of these viruses, and in the character of the lesions produced by them in experimental animals. Although certain differences in the morphological and antigenic properties of the viruses and in the disease they produce in experimental animals have suggested that they are not identical (16 to $18,23,24)$, these observed differences are less impressive than the similarities. Because of the obviously close relationship of the viruses and because of their tendency to produce latent infections with the persistence of immunological phenomena, rigid diagnostic criteria must be fulfilled before one can state that a given acute infection is caused by a member of this group of agents.

This report concerns itself primarily with the incidence of infections caused by strains of the psittacosis virus among patients with atypical pneumonia, who were encountered in a random sampling of the disease in large eastern urban areas.

\section{MATERIALS AND METHODS}

Serological studies. Samples of patients' sera were studied for antibodies against the viruses of psittacosis, lymphocytic choriomeningitis, influenza $A$, and influenza B. Titrations of influenza antibodies were made by Dr. F. L. Horsfall, Jr., of the Rockefeller Hospital as part of a coöperative investigation on the etiology of atypical pneumonia.

Psittacosis. Psittacosis antigen for complement fixation titrations with patients' serum was prepared from agar slant culture material (25), infected with the $6 \mathrm{BC}$ strain of virus isolated from a parakeet by Dr. K. F. Meyer in 1941. Our methods for the preparation of suspensions of washed inactive virus and our technique of complement fixation are modifications of those recommended by Meyer and Yanamura (26). Antigen is prepared as follows: Infected tissue is removed from the agar surface of one 
Kolle flask, which had been inoculated 5 days previously with minced chicken embryo tissue and culture virus, and triturated with $50 \mathrm{cc}$. of buffered water, i.e., S $\phi$ rensen's phosphate buffer, $\mathrm{pH} 7.6$, diluted $1: 50$. The tissue suspension is centrifuged in $25 \mathrm{cc}$. amounts in $50 \mathrm{cc}$. centrifuge tubes, at 3000 r.p.m., for 10 minutes in the International machine. The supernatant fluid is saved for high speed centrifugation and the sediment is thoroughly resuspended in $40 \mathrm{cc}$. of buffered water and recentrifuged; again the supernatant fluid is saved. The fluid obtained from the first centrifugation is placed in capped lusteroid tubes and spun at 12,400 r.p.m., in the angle centrifuge of Pickels (27), for 30 minutes in the cold room. The supernatant fluid is discarded and the sediment material is resuspended, by means of a capillary pipette, in the fluid saved from the second preliminary run in the International machine. This suspension is again spun at 12,400 r.p.m. for 30 minutes, and the resultant sediment is resuspended in $50 \mathrm{cc}$. of physiological saline solution, buffered at $\mathrm{pH}$ 7.6. This preparation of washed virus is freed of large aggregates by a final centrifugation at 2000 r.p.m. for 10 minutes. A portion of the material is saved for a titration of its infectivity; such material, when inoculated into mice by the intracerebral route, generally has a titration endpoint of $10^{-7}$ to $10^{-8}$. The suspension of virus is rendered non-infectious by heating in a steam bath at $100 \mathrm{C}$. for 30 minutes. Only non-infectious antigens are used in the complement-fixation tests.

The complement-fixation test is performed as follows: $0.2 \mathrm{cc}$. amounts of antigen, 2 units, are mixed with 0.2 cc. volumes of serial two-fold dilutions, beginning at $1: 8$, of the serum to be tested, and then $0.5 \mathrm{cc}$. of diluted complement, 2 units titered in the presence of antigen, are added. After the mixture has been incubated for $21 / 2$ hours at $37 \mathrm{C}$., the hemolytic system is added; this consists of $0.2 \mathrm{cc}$. of hemolysin appropriately diluted to contain 2 units and 0.5 cc. of a 2 per cent suspension of washed sheep erythrocytes. The test materials are incubated at $37^{\circ} \mathrm{C}$. for one-half hour when final readings are made. Titration end points are estimated on the basis of the last tube showing complete or three plus fixation, and the titer represents the dilution of serum originally added to that tube. In addition to the controls usually employed in complement fixation tests, each serum is titered against a control antigen which is prepared in exactly the same way as the test antigen, except that the culture flask is not infected with virus.

Lymphocytic choriomeningitis. Soluble antigen of lymphocytic choriomeningitis was employed in the complement fixation tests for antibodies against this virus infection. Instead of our usual technique (28) for demonstrating fixation with choriomeningitis materials, a modification of the procedure described for the psittacosis test was adopted in order to simplify the work. The two methods gave equally satisfactory results with choriomeningitis, but the former was less desirable for psittacosis. Samples of serum from each patient were titered for antibodies against the soluble antigen of choriomeningitis over the range of dilutions from $1: 2$ to $1: 32$. Pre- vious work had demonstrated that these immune substances are detectable in human sera during only a few weeks in convalescence, i.e., usually between the third and sixth weeks (28). Therefore, results were recorded as negative only for those patients whose sera taken during this period failed to fix complement in the presence of soluble antigen.

Influenza $A$ and $B$. Samples of serum were titered for antibodies against influenza $A$ and $B$ by means of the agglutination-inhibition technique of Hirst (29). Serial two-fold dilutions of the serum to be tested were prepared, and to $0.5 \mathrm{cc}$. amounts of each dilution were added 0.5 cc. volumes of suspensions of A and B virus, obtained from allantoic fluid of infected eggs; the PR-8 and Lee strains, respectively, were employed. Suspensions of virus for the test were known to contain 4 units of active material, i.e., 4 times the concentration which caused clumping of 50 per cent of the chicken erythrocytes in a test suspension (29). One cc. amounts of a 1.5 per cent suspension of washed chicken red cells were then added to the serum-virus mixtures, and readings were made after the tests had stood for an hour at room temperature. The titer of antibody was taken as the highest dilution of serum which was capable of inhibiting the agglutination reaction sufficiently to prevent the aggregation of half the red cells.

The diagnostic importance of demonstrating a rise in titer of antibodies of influenza viruses in the sera of patients during convalescence has been emphasized (30); therefore, whenever possible, a sample of serum taken during the first few days of illness and one taken later were tested. When this was not feasible, the antibody levels in single convalescent sera were determined. While too great diagnostic significance cannot be attached to the results obtained with a single serum, certain ranges of antibody levels have been reported for apparently normal individuals (31). Therefore, one can say that the titers are within the normal limits and that the patient probably had not had a recent infection, or that the antibody level for one of the viruses is distinctly elevated and that the patient may have had contact with this virus within the last few months.

Isolation of psittacosis virus. Isolation of virus from human material was attempted in only a few instances; this was due in part to the scarcity of proper specimens. For example, only one of the 2 patients who contracted psittacosis from infected pigeons of the G. flock coughed up sputum and this individual produced only 2 specimens; yet both patients presented $\mathbf{x}$-ray evidence of extensive pulmonary consolidation. Specimens for virus studies, i.e., sputum, throat washings, and lung tissue, were stored at $-70 \mathrm{C}$., generally until the results of serological tests were available. Only materials from the patients whom we suspected of having psittacosis were examined in our laboratory. Specimens from patients with atypical pneumonia unassociated with psittacosis were investigated by Dr. F. L. Horsfall; Jr.

A study of the characteristics of the strains of virus of the psittacosis group which were isolated from the 2 
patients A. G. and B. T., and from the pigeons of the G. flock, is in progress. It need only be stated at this time that strains isolated from these sources have many properties in common with the strains of psittacosis virus isolated from psittacine birds (32) and from pigeons (21), and with the virus of meningopneumonitis (16).

\section{RESULTS}

Previous experimental studies on the etiology of atypical pneumonia have generally dealt with small outbreaks of the disease (10 to 14 ) or with individual cases in whom a history of contact with sick birds suggested the possibility of psittacosis (22). A somewhat different approach to the problem was made in the present investigation. Cases of atypical pneumonia sporadically distributed in several large eastern cities were selected at random and investigated with the object of determining the incidence of infection with certain of the viruses which might be expected to cause pulmonary involvement. We were interested primarily in disease produced by members of the psittacosis group of viruses, but also investigated the possible role of the viruses of lymphocytic choriomeningitis and of influenza A and B as etiological agents of the atypical pneumonia present in our patients. We have been impressed by the high incidence of psittacosis in such patients and by the frequency with which some sort of association can be demonstrated between the patients and non-psittacine birds, infected with one of the psittacosis group of viruses.

\section{Atypical pneumonia caused by the virus of psittacosis}

The clinical picture observed in patients with psittacosis infection varied considerably; moreover, no distinguishing features were encountered in this group which permitted a clean cut separation of these patients from the group of individuals who had atypical pneumonia due to some other cause. In a like manner, histopathological examination of human lung tissue failed to reveal significant differences between the pulmonary lesions seen in the one specimen from which psittacosis virus was isolated and in the two specimens from which the virus was not obtained. The lesions in all three instances were like those described by McCordock and Muckenfuss as characteristic of the response of lung tissue to infection with a number of viruses (33). In brief, the clinical and pathological findings in our group of sporadic cases of atypical pneumonia of known and unknown etiology were similar. Furthermore, our patients resembled in most repects those observed by Kneeland and Smetana (6) and by Longcope (7).

Emphasis has already been laid on the difficulties encountered in establishing proof of recent infection with a virus of the psittacosis group. Formerly, the demonstration, in a single sample of convalescent serum, of complement fixing antibodies which reacted with psittacosis antigen was considered adequate for diagnosis. Evidence of this nature is no longer conclusive in view of the ubiquity of agents capable of eliciting such antibodies, and of the long interval of time that these antibodies may persist. Therefore, certain minimal criteria have been selected arbitrarily as essential for the proof that a given illness is caused by a strain of psittacosis virus. These are (1) isolation of virus during the acute phase of the disease, or (2) the demonstration of the appearance of complement fixing antibodies during convalescence or of a significant rise in titer of these antibodies during the period of recovery. In other words, it is now imperative to adopt the same type of criteria for the diagnosis of psittacosis that previously has been found necessary for lymphocytic choriomeningitis (34) and influenza (30).

Technical difficulties involved in work with undiluted human sera in the test used for psittacosis have now led us to begin our titrations for psittacosis antibodies with a 1:8 dilution of serum. For a given specimen to be considered positive in our laboratory, it must give complete fixation in a dilution of serum of $1: 16$ or greater. Significance is attached to a rise in antibody titer during convalescence only if the increase is fourfold or more. Furthermore, for a mere fourfold increase to be considered valid, the early and late samples of serum must be tested in the same experiment.

Ten persons, among the 45 from eastern cities who had atypical pneumonia, suffered from psittacosis. Stated another way, on the basis of the criteria enumerated in the preceding paragraph, infection with a strain of psittacosis virus was proved to have been associated with the illness of almost one-fourth of the members of the group of 







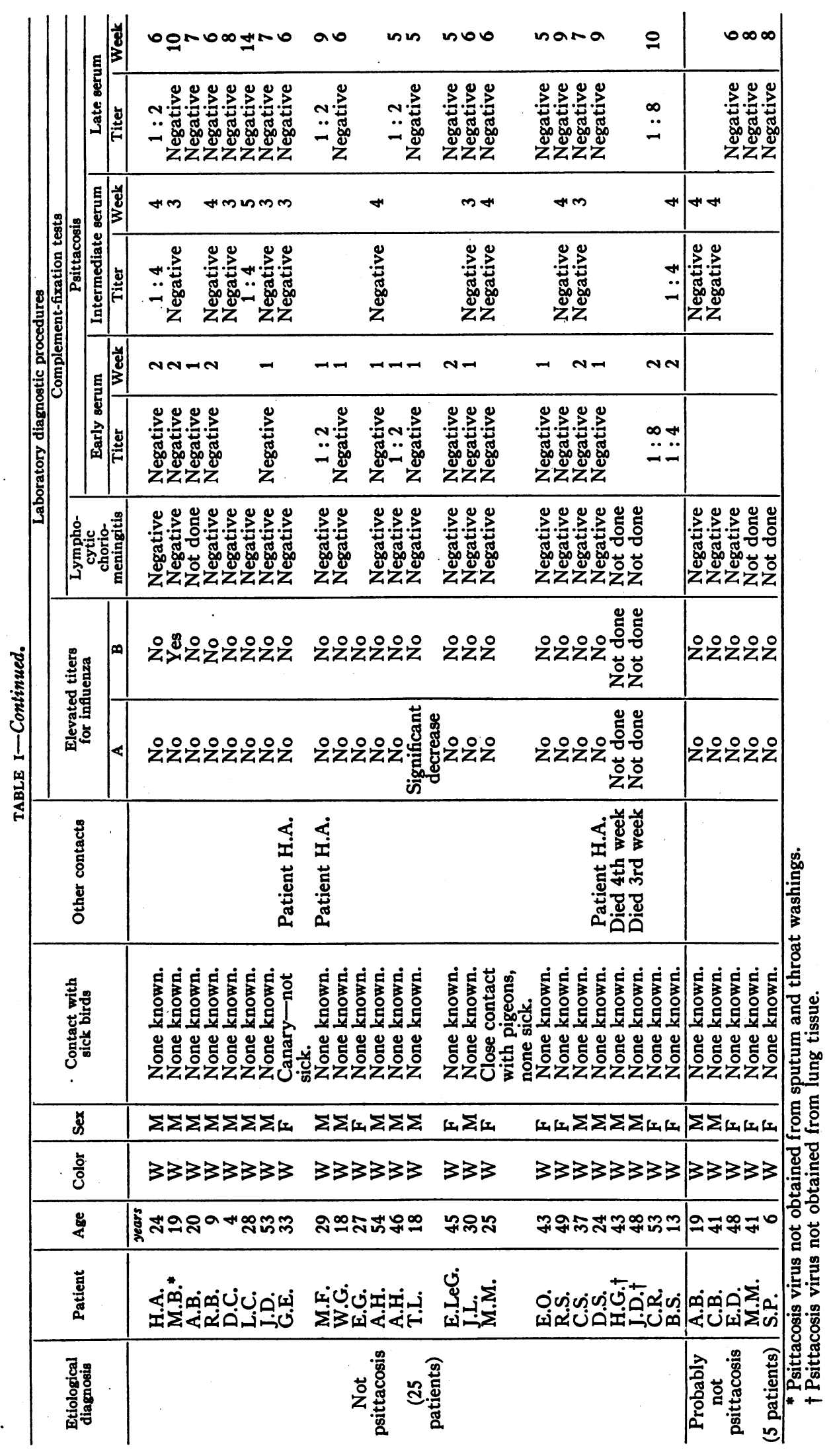


sporadic cases of atypical pneumonia. A virus of the psittacosis family was isolated from sputum of one patient and from lung tissue of another. The diagnosis of psittacosis which was made on the remaining 7 persons depended entirely on results of serological studies. A summary of pertinent data on the 10 cases of proved psittacosis is included in Table I, together with information on the findings in the remaining 35 members of the group with atypical pneumonia.

Psittacosis virus may have been of etiological importance in $\mathbf{5}$ additional patients with atypical pneumonia but this remains unproved. Only the results of serological investigations implicate the virus in the disease of these 5 individuals, and, although each person had significant amounts of complement fixing antibodies in his convalescent serum, none developed a fourfold increase in titer of these substances during the period of study. It is not unlikely that we have been too drastic in our choice of minimal standards for the diagnosis of psittacosis infections in human beings, and that some or all of these 5 patients should be included as cases of psittacosis. Indeed, Meyer (20) did not hesitate to make the diagnosis of psittacosis in 2 women (O. W. and E. W., patients of Dr. George S. Mirick of the Rockefeller Hospital) on the basis of his serological studies, although the evidence in these 2 instances was no more impressive than that obtained on C. M. and F. S. (Table I). Nevertheless, until increased experience is gained in this field where serological reactions are so involved, it seems preferable to maintain a conservative viewpoint.

\section{Atypical pneumonia unassociated with psittacosis}

Thirty of the 45 persons with atypical pneumonia presented no evidence of recent infection with a virus of the psittacosis group (Table I). Several samples of serum, taken at intervals after onset of pneumonia, were available from 23 of the 30 patients; none of these sera contained appreciable amounts of antibodies which reacted with psittacosis antigen. Lung tissue obtained at postmortem examination from 2 of the 30 persons, and throat washings and sputum from another patient who recovered, all failed to yield a virus of the psittacosis group despite persistent efforts of the type which had proved successful with material from other patients. Single specimens of serum, drawn during the second month of convalescence, were available from 5 patients; these also gave negative results in our test for antibodies of psittacosis.

It is axiomatic in virus research that a negative result, i.e., the failure to isolate a viral agent or to demonstrate an immune response in a host, is less significant than a positive result. Therefore, one can only say that it is highly unlikely that 25 patients (23 from whom several samples of serum were obtained and 2 who died) of the group had an infection with the virus in question. Discussion might arise concerning the validity of the assumption that psittacosis was unrelated to the illness of those 5 individuals whose serum was examined only between the 4 th and 8 th weeks. It is our experience, as well as that of others (35), that complement fixing antibodies generally persist in high titer for many weeks after infection with the virus of psittacosis. Therefore, we feel justified in our opinion that a negative result in the psittacosis test on serum taken rather late in convalescence is of considerable value in ruling out the diagnosis of psittacosis. This is in contrast to the diagnostic value that may be assigned to the demonstration of psittacosis antibodies in a single sample of blood, drawn during this same period of recovery.

Serological investigations, undertaken to determine the incidence of influenza A and B and of lymphocytic choriomeningitis in the entire group of patients with atypical pneumonia, gave essentially negative results in all except 2 instances. None of the 37 patients on whom adequate material was available possessed demonstrable antibodies against antigen of choriomeningitis. Both of the persons who showed deviations from the normal levels of influenza antibodies were encountered in the group of patients in whose disease psittacosis was not a factor. Serum of one of these, M. B., had a high titer of antibodies for influenza $B$ virus $(1: 768)$ as early as the 9 th day, and this level did not change materially during the 10 weeks of observation. Serum from the other patient, T. L., showed an influenza A antibody level of $1: 364$ on the 6 th day, and $1: 64$, four weeks later. It is possible that these 2 individuals had recent infections with the viruses of 
influenza $B$ and $A$ respectively, but the data are insufficient to prove that such infections were responsible for the pulmonary disease.

\section{Epidemiological observations}

The source of infection was clearly evident in 2 of the patients with psittacosis. Both A. G. and E. G. handled acutely ill pigeons during the course of an epizoötic disease in their flock, which was caused by a virus of the psittacosis group. The incubation period of the disease in both patients was approximately 3 weeks; a more detailed description of the human and avian infection will be reported (36). Similarly, patient J. M. in all probability derived his psittacosis from pigeons. Two of 6 birds in J. M.'s flock had complement fixing antibodies that reacted with psittacosis antigen. Therefore, a latent infection was undoubtedly present among the pigeons even though none of the birds was obviously sick. The occasional exposure of patient $R$. L. to pigeons occurred when he visited a friend while the latter "flew" his birds; this may have been the source of his infection but none of the pigeons was available for examination.

It seems worthwhile to record certain observations on the direct and indirect exposure of patients with atypical pneumonia, to birds, some of which had latent psittacosis. These data are presented only to emphasize the need for further study, since no conclusions may be drawn at this time. Three additional patients among the 10 who had psittacosis, and one patient in the group of 5 who may have had this disease, were either in direct contact with birds or had a remote connection with them, preceding the onset of atypical pneumonia. Mention need hardly be made of patients B. T. and C. M., see Table I, who were exposed to apparently healthy canaries. This avian species has been known to transmit infection to man; moreover, B. T. visited bird stores to purchase food for her canaries and may have been exposed to classical psittacine strains of the virus. The epidemiological importance of indirect exposure over long periods of time to pigeons with latent psittacosis must be considered. For example, E. Gu. and J. W. lived nearby flocks of pigeons but neither person handled the birds or even visited the lofts. It must be borne in mind that not all patients who are associated with birds have atypical pneumonia and psittacosis, viz., G. E. and M. M. in Table I.

Finally, the question arises concerning the source of infection of 3 proved cases of psittacosis and of 4 cases of atypical pneumonia who may have had psittacosis, since none of these individuals had any known contact with birds. Of course, numerous flocks of pigeons are present in all metropolitan areas and previous observations $(21,24)$, as well as present ones, indicate a high degree of parasitism of such birds with strains of the virus of psittacosis. Therefore, it is possible, as Meyer, Eddie, and Yanamura suggest (21), that these individuals were infected by inhaling contaminated material during transient indirect exposure to acutely ill or latently infected pigeons. On the other hand, it appears desirable to search for a humanized strain of virus of this general group which is moderately contagious for man and which is transmitted from man to man by way of the upper respiratory route. A family of viruses, as widely disseminated throughout the avian, mammalian, and human species as is the psittacosislymphogranuloma venereum group of agents, might be expected to possess a member with potentialities of this type.

Differences were noted in the age and sex distribution of our cases with psittacosis and with atypical pneumonia of unknown etiology. The average age of the patients with proved or suspected psittacosis was 49 years, and 9 of the 15 individuals were females. In contrast, the average for the patients with atypical pneumonia unassociated with psittacosis was 31 years, and only 11 of the 30 persons were females. In this small series of cases of atypical pneumonia, the incidence of psittacosis among pigeon fanciers, most of whom are men, and among middle aged women, many of whom are fond of pets, is impressively high.

\section{DISCUSSION}

The present work indicates that an appreciable number, approximately one-fourth, of the sporadic cases of atypical pneumonia are caused by infection with strains of the virus of psittacosis. It also indicates that about two-thirds of the patients present no evidence of infection with members of 
the psittacosis group of viruses. Diagnostic difficulties are encountered among the patients who early in the course of their disease possess antibodies that fix complement in the presence of psittacosis antigen, but who develop no notable increase in the titer of these antibodies during convalescence. At the present time, one is not justified in assuming that infection with strains of the virus of psittacosis is responsible for the pneumonic disease in this group of patients. Our observations on sera of patients with lymphogranuloma venereum are in agreement with those of Rake, Eaton and Shaffer (16), viz., antibody in the sera of such individuals fixes complement with psittacosis antigen. Accordingly, rigid criteria have been established which must be fulfilled for each patient before we are willing to say that psittacosis virus is of etiological importance in that person's illness.

In this paper, the term "psittacosis" has been applied to the disease of the patients with atypical pneumonia caused by a psittacosis-like virus. Furthermore, reference has been made repeatedly to infection with strains of the virus of psittacosis. These expressions have been used because we think that the viruses isolated in our laboratory from human beings and from pigeons have so much in common with classical psittacosis virus that they are merely strains of this agent. Similarly, we would designate the viruses described by others as meningopneumonitis (19), pneumonitis $(13,16)$, and ornithosis (21) as strains of the virus of psittacosis. Certainly, the differences between the agents just mentioned are no greater than those found among the strains of a number of viruses. As an example, one need only mention the virus of vaccinia with its numerous strains, some of which differ strikingly from the classical agent isolated from lesions of cowpox. If only the strains of virus discussed above constituted a specific group, then there might be justification for dividing the human disease which they cause into psittacosis and ornithosis, as Meyer has done $(21,22)$. However, we must reckon with the viruses of lymphogranuloma venereum and of mouse pneumonitis (37) (and undoubtedly others yet to be discovered), for they too belong in the family. Therefore, until sufficient data have accumulated to warrant a reason- able taxonomic approach to this confusing problem, it seems preferable to employ the term psittacosis-lymphogranuloma virus for this entire group, just as the expression vaccinia-variola virus is applied to that group of agents. Furthermore, until the situation is clarified, it appears reasonable to speak of the members of the family as strains of the viruses of psittacosis and of lymphogranuloma venereum, depending upon which one of these the agent in question resembles more closely.

\section{SUM MARY}

Ten of the 45 sporadic cases of atypical pneumonia encountered among large eastern urban populations were caused by infection with strains of the virus of psittacosis. Five additional cases in the series may have had psittacosis but the diagnosis was indefinite because of the failure to demonstrate a significant rise in antibody titer in the convalescent sera of these patients. In no instance was the virus of lymphocytic choriomeningitis associated with the illness of individuals in the group, and in only two instances was influenza virus even suspected as a possible etiological agent.

The importance of establishing an etiological diagnosis in cases of atypical pneumonia is emphasized and the essential laboratory data necessary for such a diagnosis are discussed.

The author wishes to thank Miss Margaret J. Wall and Miss Elizabeth M. Kolb for their valuable assistance.

\section{BIBLIOGRAPHY}

1. Allen, W. H., Acute pneumonitis. Ann. Int. Med., 1936, 10, 441.

2. Scadding, J. G., Disseminated focal pneumonia. Brit. M. J., 1937, 2, 956.

3. Reimann, H. A., An acute infection of the respiratory tract with atypical pneumonia. A disease entity probably caused by a filterable virus. J. A. M. A., 1938, 111, 2377.

4. Smiley, D. F., Showacre, E. C., Lee, W. F., and Ferris, H. W., Acute interstitial pneumonitis: a new disease entity. J. A. M. A., 1939, 112, 1901.

5. Reimann, H. A., and Havens, W. P., An epidemic disease of the respiratory tract. Arch. Int. Med., $1940,65,138$.

6. Kneeland, Y., Jr., and Smetana, H. F., Current bronchopneumonia of unusual character and undetermined etiology. Bull. Johns Hopkins Hosp., 1940, 67, 229. 
7. Longcope, W. T., Bronchopneumonia of unknown etiology (variety X). A report of 32 cases with 2 deaths. Bull. of Johns Hopkins Hosp., 1940, 67, 268.

8. Hornibrook, J. W., and Nelson, K. R., An institutional outbreak of pneumonitis. I. Epidemiological and clinical studies. Pub. Health Rep., 1940, 55, 1936.

9. Gallagher, J. R., Acute pneumonitis. A report of 87 cases among adolescents. Yale J. Biol. and Med., 1941, 13, 663.

10. Adams, J. M., Primary virus pneumonitis with cytoplasmic inclusion bodies. Study of an epidemic involving 32 infants, with 9 deaths. J. A. M. A., 1941, 116, 925.

11. Dyer, R. E., Topping, N. H., and Bengtson, I. A., An institutional outbreak of pneumonitis. II. Isolation and identification of causative agent. Pub. Health Rep., 1940, 55, 1945.

12. Weir, J. M., and Horsfall, F. L., Jr., The recovery from patients with acute pneumonitis of a virus causing pneumonia in the mongoose. J. Exper. Med., 1940, 72, 595.

13. Eaton, M. D., Beck, M. D., and Pearson, H. E., A virus from cases of atypical pneumonia. Relation to the viruses of meningopneumonitis and psittacosis. J. Exper. Med., 1941, 73, 641.

14. Stokes, J., Jr., Kenney, A. S., and Shaw, D. R., A new filtrable agent associated with respiratory infections. Tr. Coll. Phys. Phila., 1938-1939, 6, 329.

15. Cecil, R. L., editor, A Textbook of Medicine. W. B. Saunders, Philadelphia, 1940, 5th edition, pp. 66-67 (Rivers, T. M., on Psittacosis).

16. Rake, G., Eaton, M. D., and Shaffer, M. F., Similarities and possible relationships among viruses of psittacosis, meningopneumonitis, and lymphogranuloma venereum. Proc. Soc. Exper. Biol. and Med., 1941, 48, 528.

17. Pinkerton, H., and Moragues, V., Comparative study of meningopneumonitis virus, psittacosis of pigeon origin, and psittacosis of parrot origin. J. Exper. Med., 1942, 75, 575.

18. Eaton, M. D.; Martin, W. P., and Beck, M. D., The antigenic relationship of the viruses of meningopneumonitis and lymphogranuloma venereum. $\mathrm{J}$. Exper. Med., 1942, 75, 21.

19. Francis, T., Jr., and Magill, T. P., An unidentified virus producing acute meningitis and pneumonitis in experimental animals. J. Exper. Med., 1938, 68, 147.

20. Meyer, K. F., Pigeons and barn yard fowls as possible sources of human psittacosis or ornithosis. Schweiz. med. Wchnschr., 1941, 71, 1377.

21. Meyer, K. F., Eddie, B., and Yanamura, H. Y., Ornithosis (psittacosis) in pigeons and its relation to human pneumonitis. Proc. Soc. Exper. Biol. and Med., 1942, 49, 609.
22. Meyer, K. F., The ecology of psittacosis and ornithosis. Medicine, 1942, 21, 175.

23. Rake, G., Jones, H. P., and Nigg, C., Sulfonamide chemotherapy of mouse pneumonitis, meningopneumonitis, and lymphogranuloma venereum. Proc. Soc. Exper. Biol. and Med., 1942, 49, 449.

24. Eddie, B., and Francis, T., Jr., Occurrence of psittacosis-like infection in domestic and game birds of Michigan. Proc. Soc. Exper. Biol. and Med., 1942, 50, 291.

25. Yanamura, H. Y., and Meyer, K. F., Studies on the virus of psittacosis cultivated in vitro. J. Infect. Dis., 1941, 68, 1.

26. Meyer, K. F., and Yanamura, H. Y., Personal communiation.

27. Pickels, E. G., An improved type of electrically driven high speed laboratory centrifuge. Rev. Scient. Instruments, 1942, 13, 93.

28. Smadel, J. E., and Wall, M. J., A soluble antigen of lymphocytic choriomeningitis. III. Independence of anti-soluble substance antibodies and neutralizing antibodies, and the role of soluble antigen and inactive virus in immunity to infection. J. Exper. Med., 1940, 72, 389.

29. Hirst, G. K., The quantitative determination of influenza virus and antibodies by means of red cell agglutination. J. Exper. Med., 1942, 75, 49.

30. Francis, T., Jr., Magill, T. P., Rickard, E. R., and Beck, M. D., Etiological and serological studies in epidemic influenza. Am. J. Pub. Health, 1937, 27, 1141.

31. Hirst, G. K., Rickard, E. R., Whitman, L., and Horsfall, F. L., Jr., Antibody response of human beings following vaccination with influenza viruses. $\mathrm{J}$. Exper. Med., 1942, 75, 495.

32. Rivers, T. M., and Berry, G. P., Psittacosis. II. Experimentally induced infections in mice. J. Exper. Med., 1931, 54, 105; III. Experimentally induced infections in rabbits and guinea pigs. Ibid., 1931, 54, 119; IV. Experimentally induced infections in monkeys. Ibid., 1931, 54, 129.

33. McCordock, H. A., and Muckenfuss, R. S., The similarity of virus pneumonia in animals to epidemic influenza and interstitial bronchopneumonia in man. Am. J. Path., 1933, 9, 221.

34. Scott, T. F. McN., and Rivers, T. M., Meningitis in man caused by a filterable virus. I. Two cases and the method of obtaining a virus from their spinal fluids. J. Exper. Med., 1936, 63, 397.

35. Meyer, K. F., and Eddie, B., The value of the complement fixation test in the diagnosis of psittacosis. J. Infect. Dis., 1939, 65, 225.

36. Smadel, J. E., Wall, M. J., and Gregg, A., To be published.

37. Nigg, C., An unidentified virus which produces pneumonia and systemic infection in mice. Science, 1942, 95, 49. 